\title{
BMJ Open B!RTH: a mixed-methods survey of audience members' reflections of a global women's health arts and science programme in England, Ireland, Scotland and Switzerland
}

Mary McCauley (D), Joanne Thomas, Cristianne Connor, Nynke van den Broek

To cite: McCauley M, Thomas J, Connor C, et al. B!RTH: a mixed-methods survey of audience members' reflections of a global women's health arts and science programme in England, Ireland, Scotland and Switzerland. BMJ Open 2019;9:e027531. doi:10.1136/ bmjopen-2018-027531

- Prepublication history for this paper is available online. To view these files, please visit the journal online (http://dx.doi. org/10.1136/bmjopen-2018027531).

Received 31 0ctober 2018 Revised 26 November 2019 Accepted 27 November 2019

Check for updates

(C) Author(s) (or their employer(s)) 2019. Re-use permitted under CC BY-NC. No commercial re-use. See rights and permissions. Published by BMJ.

Centre for Maternal and Newborn Health, Liverpool School of Tropical Medicine, Liverpool, UK

Correspondence to Dr Mary McCauley; mary.mccauley@Istmed.ac.uk

\section{ABSTRACT}

Objective Public engagement and science communication are growing as an important forum in the design and dissemination of research. The B!RTH programme is a partnership that uses theatre in combination with scientific expert panel discussions to raise awareness about the global inequality in women's health and access to healthcare. As part of this project, we assessed the views and experiences of audiences participating in $\mathrm{B} ! \mathrm{RTH}$ events.

Design We conducted a multi-site mixed-methods survey using paper-based questionnaires.

Settings Data were collected at four B!RTH theatre and science events: Dublin (Ireland), Edinburgh (Scotland), Geneva (Switzerland) and Liverpool (England) after the performance of four plays and three expert panel discussions.

Participants All audience members.

Methods Descriptive analysis was conducted for the responses to the closed-ended survey questions, and thematic analysis was used for written free text provided. Results The estimated response rate was 42\%; 363 members of the audiences responded. Most respondents had been emotionally moved by the performances $(92.8 \%)$ and felt challenged and provoked $(80.7 \%)$. Many respondents $(73.6 \%)$ agreed that their eyes had been opened by new ideas. Five themes emerged from the free-text analysis: (1) an expression of thanks and positive feedback on the content and performance of the plays, (2) the benefit of and innovative use of art and science, (3) personal feelings in response to the plays and panel discussions, (4) the need for action and (5) suggestions for use of the plays and panel discussions in schools and universities to 'bring to life the human story behind the statistics'.

Conclusions The B!RTH programme highlights how art and science can be used in partnership and is an effective tool to engage the public, to deliver key messages and to raise awareness about inequalities in global maternal and reproductive healthcare issues.

\section{INTRODUCTION}

Each year, an estimated 303000 women around the world die because of complications due
Strengths and limitations of this study

- We assessed the views of a large number of audience members (363) across four different countries.

- We used closed-ended questions and also provided space for written free text on the paper questionnaires, to ensure audience members were able to give personal feedback.

- It was challenging to determine the exact response rate of those who completed the questionnaire, as there was no register for the total number of audience members at each venue.

- All members of the audience chose to attend the art and science event, and this may represent a biased population sample due to self-selection.

to pregnancy and/or childbirth. ${ }^{1}$ In addition, 2.6 million babies are stillborn each year and a further 2.8 million babies die in their first month of life. ${ }^{1}$ Most $(99 \%)$ of these deaths occur in low-income and middle-income countries (LMIC) settings, and many could be prevented or avoided through actions that are proven to be effective and affordable, for example, access to a skilled birth attendant. ${ }^{1}$ Women are at a much higher risk of dying during or after childbirth in a LMIC, compared to a high-income country, such as the UK. For example, it is estimated that for every 100000 babies that are born in Sierra Leone, 1360 women die; in the UK this number is nine. ${ }^{1}$ These figures reflect inequality in the access to, availability and quality of healthcare for women during pregnancy and childbirth. These statistics inspired the development of an arts and science partnership to raise awareness and debate regarding these inequalities.

In 2016, a new and unique collaboration, the B!RTH programme, was established. ${ }^{2}$ This programme consisted of a multidisciplinary 
Table 1 Issues highlighted in four of the B!RTH plays and expert panel discussions

\begin{tabular}{|c|c|c|c|}
\hline Title of play & Issues highlighted in the play & $\begin{array}{l}\text { Issues discussed at panel } \\
\text { discussion }\end{array}$ & Venue delivered \\
\hline 'Ouroboros' (India) & $\begin{array}{l}\text { Population control. } \\
\text { Forced sterilisation. } \\
\text { Maternal deaths due to } \\
\text { unhygienic practices. } \\
\text { Maternal mortality. } \\
\text { Maternal morbidity. } \\
\text { Poor quality of surgical } \\
\text { care. }\end{array}$ & $\begin{array}{l}\text { Need for an increase in } \\
\text { women's reproductive and } \\
\text { sexual health. } \\
\text { Increase in evidence based } \\
\text { medicine. } \\
\text { Gender inequality. }\end{array}$ & $\begin{array}{l}\text { Edinburgh Fringe Festival in } \\
\text { Scotland. }\end{array}$ \\
\hline $\begin{array}{l}\text { 'Orchid' } \\
\text { (Kenya) }\end{array}$ & $\begin{array}{l}\text { Obstetric fistula. } \\
\text { Iatrogenic fistula. } \\
\text { Female genital mutilation. } \\
\text { Long-term maternal } \\
\text { morbidity. } \\
\text { Preventable severe } \\
\text { complications of childbirth. } \\
\text { Poor quality of life. } \\
\text { Lack of access to } \\
\text { specialised surgery care. } \\
\text { Stigma and taboo } \\
\text { surrounding women's } \\
\text { sexual health }\end{array}$ & $\begin{array}{l}\text { Increase in quality of care } \\
\text { at healthcare facility level. } \\
\text { Increase in skilled birth } \\
\text { attendants. } \\
\text { Increase in women's } \\
\text { reproductive and sexual } \\
\text { health. } \\
\text { Advocacy. } \\
\text { Increase in evidence-based } \\
\text { medicine. }\end{array}$ & $\begin{array}{l}\text { WHO in Geneva, Switzerland } \\
\text { and Liverpool, England. }\end{array}$ \\
\hline $\begin{array}{l}\text { 'Q \& Q' } \\
\text { (Syria) }\end{array}$ & $\begin{array}{l}\text { Violence against women. } \\
\text { Human trafficking. } \\
\text { Sex trafficking. } \\
\text { Abuse of reproductive } \\
\text { rights. } \\
\text { Vulnerability of women in } \\
\text { conflict and war. }\end{array}$ & $\begin{array}{l}\text { Increase in women's } \\
\text { reproductive and sexual } \\
\text { health. } \\
\text { Advocacy. } \\
\text { Eliminate violence against } \\
\text { women. }\end{array}$ & $\begin{array}{l}\text { WHO in Geneva, Switzerland } \\
\text { and Liverpool, England. }\end{array}$ \\
\hline
\end{tabular}

team including a creative director, playwrights, maternal health researchers and programme managers who created and delivered a series of seven plays to ignite debate, inspire action and encourage positive social change. Each play was set in a different country and highlighted a range of problems and issues that women faced in that particular context, for example: physical, psychological and social ill-health related to pregnancy and childbirth, obstetric fistula, female genital mutilation, infertility, abortion, maternal death and lack of reproductive health choices $^{2}$ (table 1$)$.

Public or community engagement is two-way open communication between scientific researchers and the public on a local, national and international level, to generate mutual benefit. ${ }^{3}$ As a concept, public engagement is gaining prominence as a priority for many researchers, with an increase in awareness that early engagement with stakeholders and beneficiaries can help to generate powerful new knowledge and promote conversation and debate to inspire learning and reflection. ${ }^{3}$ By acting as partners in research, when appropriate, members of the public can provide insight and expertise to help generate innovation and support decision-making to make the research relevant, practical and motivating. ${ }^{5}$ Science communication using theatre has been used by researchers to disseminate key messages and promote public engagement. ${ }^{6} 7$ For example, there are studies describing how theatre-based interventions (eg, improvisation, role-play, vignettes) have been used as health education methods to communicate information and engage audience members in health topics such as substance misuse, sexual health, obesity and mental health illness. $^{8-14}$ However, there is a lack of understanding of how best art and theatre can be used, and how to assess the impact on audience members, especially regarding women's health and healthcare in different settings. One of the objectives of the B!RTH programme is to increase awareness in relation to global women's health 
issues through theatre, and to encourage audiences to engage with these issues. To the best of our knowledge, no project to date has explored audience views or experiences regarding plays related to global maternal and reproductive health inequalities. We therefore sought to assess the views and experiences of audience members, who had just watched a play and/or been involved in an expert panel discussion as part of the B!RTH programme.

\section{METHODS}

\section{Study design}

We conducted a survey using three types of data collection tools: (1) paper-based questionnaire with five questions and an option for free text; (2) paper-based questionnaire with 11 questions, an option for free text and questions on respondent demographics; (3) pop-up stands to provide an electronic 'stars' rating.

\section{Settings}

The B!RTH programme was delivered at four venues as part of different festivals and events between August 2016 and November 2018: (1) Dublin Fringe Festival, Ireland; (2) Edinburgh Fringe Festival, Scotland; (3) WHO, Geneva, Switzerland; and (4) the Liverpool School of Tropical Medicine (LSTM), Liverpool, England. Different plays, each lasting on average 30 minutes, were delivered at different venues (table 1). At three venues, expert panel discussions with audience-generated questions were conducted after the plays. The panel members differed in each event and had relevant expertise regarding the particular issues highlighted in the plays that had just been performed (table 1). After a brief introduction from the chair and from panel members, questions were asked by the audience members. The panel members discussed possible answers, gave more information and facilitated further audience discussion around current challenges and strategies regarding global women's health.

\section{Patient and public involvement}

No patient nor members of the public were involved in the design of the survey.

\section{Data collection}

For the questionnaire, we used eight questions from a previously validated questionnaire to assess public audience response to theatre. ${ }^{15} 16$ Two variations of the questionnaire were then developed: (i) a short questionnaire with five statements, and (ii) an extended version with an additional six statements. All members of the audience were asked to respond using a five-point Likert-scale ranging from 'strongly agree' to 'strongly disagree' for each statement. In addition, there was a free-text box to give additional feedback. The five statements on the short version of the questionnaire included: (1) I learnt something new; (2) the play made me think differently about things; (3) I found aspects of the performance emotionally moving; (4) I am concerned about global inequality in childbirth; and (5) I am interested to find out more about the B!RTH programme. In addition to these five questions, further questions were added for the extended version of the questionnaire including: (6) my eyes were opened to some new ideas; (7) I felt challenged and provoked; (8) I felt I could identify with the characters/story; (9) some aspects of the performance(s) seemed relevant to my own life; (10) I found aspects of the performance(s) emotionally moving; and (11) some aspects of the performance seemed relevant to my own life. Prior to each performance, the creative director gave the audience verbal information regarding the aims and objectives of the B!RTH programme. All respondents were requested to complete either the short or extended paper-based questionnaire (not both), and at two of the events (Geneva and Liverpool), the audiences were also invited to give an electronic 'star rating'. This was captured by hitting a button on a tablet positioned at a pop-up stand at the exit of the venue.

\section{Data analysis}

Descriptive analysis was conducted for the closed-ended questions from the questionnaires. All free-text comments were coded by theme and then grouped into categories. Thematic analysis was undertaken to identify emerging themes. ${ }^{17}$ Initial open coding following data familiarisation (reading and re-reading of the free-text comments) was conducted by the primary (MMC) and secondary (JT) researchers. The free text was reviewed by a third researcher $(\mathrm{NvdB})$ to check for inter-rater reliability and to reach consensus on themes.

There was no identifiable information on the questionnaires, and implied consent was given by the return of the completed questionnaires and the completed electronic rating.

\section{RESULTS}

A total of 363 respondents responded across the four events, including completion of the short questionnaire (287), long questionnaire (76), free text (183) and electronic star rating (76). The respondents were audience members at the events in Dublin (80), Edinburgh (176), Liverpool (66) and Geneva (41) (table 2). For each performance, the total numbers of potential respondents were those who could attend the theatre, assuming maximum capacity. Based on this, the estimated overall response rate was $42 \%$.

Overall, of those who provided demographic information, $78 \%$ were women and $72 \%$ were between the ages of 18 and 50 years. The majority were of white ethnicity, and $45 \%$ had been to the theatre at least three times in the past year (table 3). Of those who provided feedback in Edinburgh, more respondents were white, older and had been to theatre more often compared to the respondents from the other three venues. The respondents in Liverpool and Geneva were younger and were more ethnically diverse. 
Table 2 Number of completed questionnaires

\begin{tabular}{lllr} 
Setting & Type of data collection & & Number of completed forms \\
\hline Dublin, Ireland & Paper based & Short questionnaire & 80 \\
& & Extended questionnaire & 0 \\
Edinburgh, Scotland & Paper based & Short questionnaire & 159 \\
& & Extended questionnaire & 17 \\
Geneva, Switzerland & Paper based & Short questionnaire & 22 \\
& & Extended questionnaire & 19 \\
Liverpool, England & Paper based & Short questionnaire & 26 \\
& & Extended questionnaire & 40 \\
Total & & 363 \\
\hline
\end{tabular}

\section{Questionnaire and star ratings}

Overall, most of the respondents were emotionally moved by the performances $(93.7 \%)$ and felt challenged and provoked $(81.6 \%)$ (figure 1). Many respondents $(73.7 \%$ ) agreed that their eyes had been opened by new ideas, and $71.9 \%$ agreed that the play had made them think differently about things. Most respondents (95.9\%) reported concern about global maternal health inequality, and many $(81.8 \%)$ were interested in finding out more about the B!RTH programme. There were no major differences ( $>5 \%$ difference in responses) between the responses given by the different types of audiences across the four venues. Electronic star ratings were used at the Geneva and Liverpool events. A total of 76 respondents provided instant feedback on leaving the venue using this system. Overall, $78 \%$ of respondents rated the event ' 5 star'; $20 \%$ ' 4 star'; and $2 \%$ ' 3 star'. No one rated the event ' 2 star' or ' 1 star'.

\section{Thematic analysis}

Of all respondents who completed the questionnaires (363), $183(50.4 \%)$ also provided additional free-text

Table 3 Characteristics of subsample of respondents who completed the extended questionnaire at each event*

\begin{tabular}{|c|c|c|c|c|}
\hline & Edinburgh, Scotland & Liverpool, England & Geneva, Switzerland & Total \\
\hline Setting & $\mathrm{n}=17$ & $\mathrm{n}=39$ & $n=18$ & $\mathrm{n}=74$ \\
\hline \multicolumn{5}{|l|}{ Gender } \\
\hline Female & $12(71 \%)$ & $30(75 \%)$ & 16 (89\%) & $58(78 \%)$ \\
\hline Male & $5(29 \%)$ & $9(25 \%)$ & $2(11 \%)$ & $16(22 \%)$ \\
\hline \multicolumn{5}{|l|}{ Age } \\
\hline $18-30$ & $1(6 \%)$ & $14(36 \%)$ & $3(16 \%)$ & $18(24 \%)$ \\
\hline $31-40$ & $1(6 \%)$ & $13(33 \%)$ & $4(22 \%)$ & $18(24 \%)$ \\
\hline $41-50$ & $3(18 \%)$ & $8(21 \%)$ & $6(33 \%)$ & $17(23 \%)$ \\
\hline $51-60$ & $7(41 \%)$ & $2(5 \%)$ & $5(27 \%)$ & $14(19 \%)$ \\
\hline$>60$ & $5(29 \%)$ & $2(5 \%)$ & 0 & $7(10 \%)$ \\
\hline \multicolumn{5}{|l|}{ Ethnic group } \\
\hline Asian/Asian British & 0 & $2(5 \%)$ & $4(22 \%)$ & $6(8 \%)$ \\
\hline Black/Black British & 0 & $10(26 \%)$ & 0 & $10(14 \%)$ \\
\hline Mixed & 0 & $4(10 \%)$ & $2(11 \%)$ & $6(8 \%)$ \\
\hline Other & 0 & $4(10 \%)$ & 0 & $4(5 \%)$ \\
\hline White & 17 (100\%) & $19(49 \%)$ & $12(67 \%)$ & $48(65 \%)$ \\
\hline \multicolumn{5}{|l|}{ Theatre views } \\
\hline 0 & 0 & $9(23 \%)$ & $4(22 \%)$ & $13(18 \%)$ \\
\hline $1-3$ & $3(18 \%)$ & $21(54 \%)$ & $9(50 \%)$ & $33(45 \%)$ \\
\hline $4-10$ & $5(29 \%)$ & $7(18 \%)$ & $4(22 \%)$ & $16(22 \%)$ \\
\hline $11+$ & 9 (53\%) & $2(5 \%)$ & $1(5 \%)$ & 12 (15\%) \\
\hline
\end{tabular}

*It was not possible to collect this data at the event in Dublin, Ireland. 


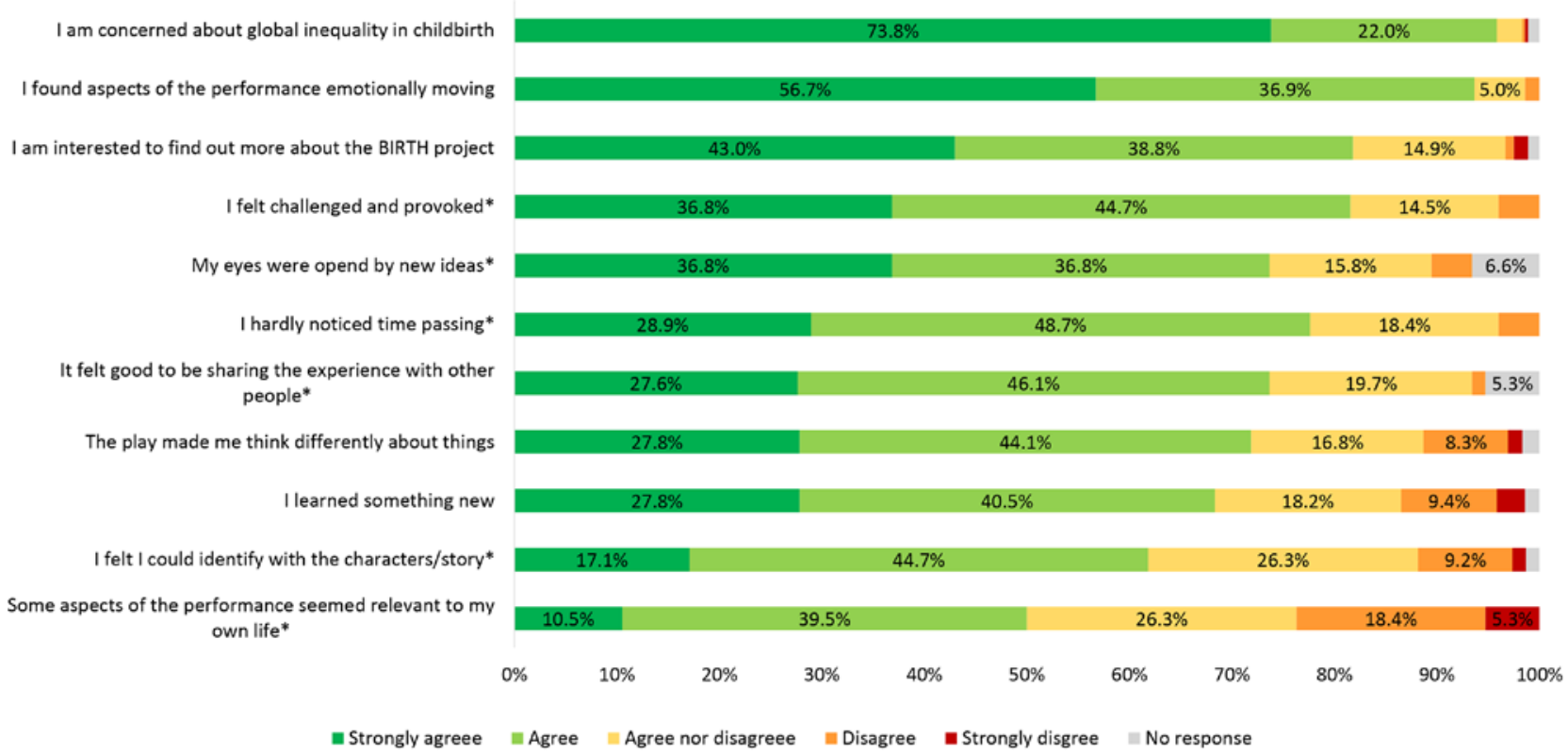

*additional questions asked in the extended version of the questionnaire

Figure 1 Combined cohort of all respondents across the four venues $(n=363)$ - short and long versions combined.(figure 1)

written feedback in the comments box of the questionnaires. The main emerging themes from the free text included: (1) an expression of thanks and positive feedback on the content and delivery of the plays, (2) the innovative use of art and science, (3) personal feelings in response to the plays and panel discussions, (4) the need for action and (5) suggestions for use of the plays in schools and universities.

Theme 1: expression of thanks and positive feedback

Many of the respondents were impressed with the content and delivery of the plays, giving praise for the standard of performance, actors and scripts.

A brilliant play very powerful pertinent and emotive. Beautifully read. Well done! (Edinburgh respondent)

Excellent performances by the artists and very moving stories. Love the creative process to raising awareness. (WHO respondent)

Respondents were encouraging of the B!RTH initiative and thanked the team for highlighting these issues.

An extraordinary event. Thank you for coming to the World Health Organization and I hope you come back again. (WHO respondent)

Amazing and so glad the unspoken is now being spoken about. (Dublin respondent)

Thank you for a great performance, I loved the creative process to raise awareness of the inequality in women's health and healthcare globally. (Edinburgh respondent)
Theme 2: innovative use of art and science

Many of the respondents were impressed with the combined use of art (plays) and science (panel discussions) to deliver the key messages and suggested this to be an effective way to educate and catalyse change.

A great way to share, inform, educate, and sensitize around these difficult issues. (WHO respondent)

Inspiring blend of art and research. This could eventually be the next movement in agenda setting for policy regulation. (Liverpool respondent)

Theme 3: personal feelings in response to the plays and panel discussions

Many of the respondents reported that they found the plays thought-provoking, engaging, eye-opening and emotionally moving.

Wonderful performance. Thoughtful; complex and challenging piece of work that forces you to confront your assumptions and expectations. (Dublin respondent)

Much to think about, I need time to digest. Moved to tears. (Edinburgh respondent)

Some respondents reported that they had learnt something new.

I was very ignorant regarding obstetric fistula before this play. I am at a loss as to why this condition is not cured as it is so easily corrected? (Liverpool respondent).

Respondents familiar with the challenges highlighted in the plays and panel discussion felt it was good to be 
reminded of the humanity behind the challenges with a renewed inspiration to keep going in their work.

Thank you for coming to the World Health Organization and bringing to life the stories we work so hard for. (WHO respondent)

A very touching play that brought the reality so close to us. It is however, encouraging to know that there are people giving all possible to bring hope to the lives of women. (WHO respondent)

However, despite feeling emotionally touched and challenged, some respondents, especially those in Edinburgh, reported a feeling of helplessness.

A powerful play that poses so many questions but leaves me feeling helpless and unable to help. (Edinburgh respondent)

My only criticism is that I am left feeling helpless and would like to know how I can help. (Edinburgh respondent)

\section{Theme 4: need for action}

Many of the respondents reported that action to address the issues raised was required and should be undertaken.

Such a moving and interesting piece of work. These conversations need to be encouraged at a public level forcing the policy-makers to take note. (Dublin respondent)

There were also requests for more discussion and debate and for further use of the plays and panel discussion in different venues and settings.

Incredible play! Please, please, please tour these everywhere and get these stories to as many people as you can! Thank you! (Dublin respondent)

The actors strongly portrayed real women's stories. I hope to see more plays and use these scripts within my own community! Thank you! (WHO respondent)

It is so difficult to move political institutions from knowledge to action and this initiative, and its outreach, is therefore vital. (Edinburgh respondent)

Theme 5: suggestions for use in schools and educational Institutes Respondents gave practical suggestions and recommendations regarding how to use the plays and panel discussion further, including the use of this concept as an educational tool in schools and universities.

Already talking about how we might teach those plays as a module at our university. (Dublin respondent)

Would love to see this project developed within schools/community groups so the discussion reaches a non-theatre going audience. Fantastic idea to have downloadable scripts and hope to see similar events in and around Edinburgh. (Edinburgh respondent)
However, a minority of respondents highlighted that some of the issues raised in the plays and panel discussion were too complex for young people to understand.

I am not sure that this project would work in schools. It is too complex for that. It would work beautifully in theatre for a well-educated audience. (Edinburgh respondent)

Other suggestions included recommending the project to colleagues and requesting video version of the plays to disseminate electronically.

I will share this project with colleagues who work around humanitarian relief. (Edinburgh respondent)

The actors were simply marvellous, and the impact was extraordinary. A great initiative. Have these performances been recorded? Would be great to disseminate. (WHO respondent)

\section{DISCUSSION}

\section{Statement of principal findings}

In this study, the use of art and science was an effective tool to facilitate public engagement and raise awareness about problems regarding global women's health issues. Members of the audiences reported that they were challenged, had learnt something new and reported that the plays and the panel discussions had made them think differently about the health inequalities faced by women globally. The response was overall positive, and many respondents were keen to engage further in the topics raised in the plays and/or panel discussions. Overall, respondents were impressed and emotionally moved by the content and delivery of the plays and appreciated the benefit and effectiveness of using art and theatre to 'bring to life the human story behind the statistics'.

\section{Strengths of the study}

To the best of our knowledge, this is the first study to assess the views and experiences of members of the audience who have seen an event that uses the partnership of plays and expert panel discussions to raise awareness of global inequality in maternal and reproductive health. The plays were presented to audiences members from research institutes (WHO and LSTM) who have the power and ability to make a change in policy and practice. The relatively large number of respondents from two art venues and two research institutes suggest that members of the audience (public, staff and students of research institutes) welcome the opportunity to give feedback and to share their experiences. This evaluation also shows that it is feasible and acceptable for respondents to provide both paper and electronic feedback during these events. This study, for the first time, provides standardised responses to validated statements, enabling comparisons between different types of audiences. A further strength of this study is that both open and closed responses was 
used, helping to document feedback that is considered important by the respondents themselves using free text.

\section{Limitations of the study}

This study used convenience sampling and is therefore limited in terms of generalisability. Furthermore, all members of the audience chose to attend the event, and this may represent a biased population sample due to selfselection. It was challenging to calculate a response rate for the questionnaires. We were unable to determine the exact response rate for the questionnaires as there were no attendance registers to document the total number of people who attended the event at each venue. As we assumed maximum capacity for each venue rather than the numbers of tickets issued (information not available), it is very likely that the response rate was in fact much greater than $42 \%$.

This study population included all members of the audience immediately after seeing a play and/or expert panel discussion and does not capture the views and reflections of the members of the audience later, when they have had more time to reflect on the issues raised during the event. Some plays were emotionally challenging, and perhaps some respondents required more time to process and then comment on the issues highlighted. However, this was primarily a pragmatic study to assess the immediate views of respondents to plays and expert panel discussions exploring the issues highlighted in the play. Details of the B!RTH website were available to audience members for those who wished to provide feedback at a later date.

\section{How does this study relate to other literature?}

There is a growing recognition of the importance of public engagement within both the arts, and science sectors and the benefits of this type of public engagement. ${ }^{36}$ The use of theatre as a public engagement tool to stimulate debate, to widen access to ideas, to engage, captivate and/or motivate an audience with scientific information has been increasing. ${ }^{5-8}$ There are many examples of health-related topics that have been highlighted using plays, including conditions such as cancer, stroke, dementia and schizophrenia. ${ }^{7-15}$ Many of these plays have been used to engage and empower those most affected by the issues highlighted in the plays, and/or involved in research, such as patients, their carer's and their healthcare providers. ${ }^{7-15}$ Other interventions have used theatre for public or community engagement to address topics such as sexual health in high-income settings, with the aim to increase communication, and challenge opinions and behaviours. For example, one study evaluated an intervention using interactive theatre to facilitate parent communication with adolescents about sexuality ${ }^{18}$ and another study reported that theatre-based interventions are a viable prevention strategy for changing sexual health knowledge, attitudes and behaviours related to HIV prevention.

The use of theatre, including drama, dance, song and plays has evolved from oral and performing arts traditions, including theatre and storytelling in many LMIC and has also more commonly been used as a tool to share information, increase communication and change knowledge attitudes and behaviours about health or science-related topics in these countries, especially in settings with lower literacy rates. ${ }^{19}{ }^{20}$ For example, community street theatre has been used as a tool for interventions on alcohol use and other behaviours related to HIV risks in a study population in the slums of Mumbai. ${ }^{21}$ Another study used teenage actors to educate parents in a community theatre setting in Timor-Leste, with significant improvements in communication, comfort and self-efficacy at follow-up and respondents' responses to the style of this presentation indicated the appropriateness of theatre as a communication tool. ${ }^{22}$ However, overall this is an area of practice largely underexplored in science communication and our study indicates that clinicians and policymakers could consider the use of theatre more widely.

With regard to maternal health, theatre and role play have been used as part of midwifery training, to challenge midwifery students to explore the perspectives of patients and reflect on the care they provide to mothers in the UK. ${ }^{23}{ }^{24}$ In such studies, midwifery students were supportive of the idea of collaborative projects and felt that the move away from a didactic approach to learning and teaching towards a more experiential model of teaching, enabled a more in-depth reflection on the importance of professional standards and behaviour when providing care to pregnant women. ${ }^{23}{ }^{24}$ However, the theatre-based interventions used in these studies have not been evaluated to demonstrate the impact on the midwifery student's overall learning.

\section{Implications for clinicians, policy-makers and researchers}

This study demonstrates the strength of theatre to engage, entertain and bring out the human stories behind the statistics that many researchers quote and policy-makers use to make decisions regarding what is needed to improve women's health and healthcare across many different countries. There is potential for the existing plays to be used more and for new plays to be developed. There is a need for further collaborative two-way engagement between members of the public and the team of playwrights and researchers of the B!RTH team. It would be useful to incorporate the results of this study to further edit and refine the B!RTH plays and agendas for the panel discussions, to ensure, for example, that medical terminology is explained in lay language.

It would be beneficial to engage members of the public in the development of new plays and B!RTH events, and to be able to support the delivery of these events in LMIC settings also. There is a need for further research as to how a sensitive approach to public engagement can be adopted to foster trust and understanding between the B!RTH events and relevant audiences. ${ }^{3}$ The B!RTH plays are free and have been made available for use as a tool for public and community engagement, and there are feedback forms available on the B!RTH website. ${ }^{2}$ There 
is, however, a need for more comprehensive, systematic monitoring and evaluation to assess the impact of theatrebased interventions as a tool on audience understanding of global women's health issues. Some respondents in our study reported feeling 'helpless' and 'at a loss of how to help', highlighting a need to be able to be guide respondents to further evidence-based information regarding what can and is being implemented to address the challenges raised as part of the plays.

\section{CONCLUSION}

The B!RTH programme is an example of an innovative platform for art and science to raise awareness and stimulate debate for the issues surrounding the global inequality in the availability and quality of care for maternal and reproductive health. The combination of arts and sciences in the B!RTH programme has worked well in this regard and highlights the strength of using theatre in combination with expert panel discussion, to ensure that women's voices and needs are heard in new and compelling ways.

\section{Twitter Mary McCauley @DrMaryMcCauley}

Acknowledgements Thank you to all the members of the audience who provided feedback at each event.

Contributors MMc conceived the study idea and design. MMc, JT and CC co-ordinated data collection in each study setting. CC performed the survey data analysis. MMc and JT performed the thematic analysis of the written free text. MMc co-ordinated the research activities, interpreted the results and wrote the manuscript. NvdB supervised the overall project, reviewed the results and contributed to the manuscript. All authors have contributed to, read, edited and approved the final manuscript for submission.

Funding This study funded by the Oglesby Charitable Trust. The funders played no role in the writing of the manuscript or the decision to submit it for publication.

Competing interests None declared.

Patient and public involvement statement No patient or members of the public were involved in the design of the survey.

Patient consent for publication Not required.

Ethics approval The Liverpool School of Tropical Medicine, Liverpool, UK, granted ethical approval (LSTM 17-038).

Provenance and peer review Not commissioned; externally peer reviewed.

Data availability statement Data are available upon reasonable request.

Open access This is an open access article distributed in accordance with the Creative Commons Attribution Non Commercial (CC BY-NC 4.0) license, which permits others to distribute, remix, adapt, build upon this work non-commercially, and license their derivative works on different terms, provided the original work is properly cited, appropriate credit is given, any changes made indicated, and the use is non-commercial. See: http://creativecommons.org/licenses/by-nc/4.0/.

\section{ORCID iD}

Mary McCauley http://orcid.org/0000-0003-1446-0625
REFERENCES

1 WHO, UNICEF, UNFPA, World Bank Group and the United Nations Population Division. Trends in maternal mortality: 1990 to 2015. estimates by WHO, UNICEF, UNFPA, world bank group and the United nations population division. Available: http://www.who.int/ reproductivehealth/publications/monitoring/maternal-mortality-2015/ en/ [Accessed July 2018].

2 B!RTH project. Available: https://www.birthdebate.com [Accessed July 2018].

3 Wellcome trust, 2011. Available: https://wellcome.ac.uk/sites/default/ files/wtvm054326_0.pdf [Accessed July 2018].

4 Dowell E, Weitkamp E. An exploration of the Collaborative processes of making theatre inspired by science. Public Underst Sci 2012;21:891-901.

5 Djerassi C. Contemporary 'science-in-theatre': a rare genre. Interdisciplinary Science Reviews 2002;27:193-201.

6 Frazzetto $\mathrm{G}$. Science on the stage: recent plays on scientific topics show that science and theatre have more in common than it appears. EMBO Rep 2002;3:818-20.

7 Taboada A, Taggart T, Holloway I, et al. A critical review of the characteristics of Theater-Based HIV prevention interventions for adolescents in school settings. Health Promot Pract 2016;17:537-47.

8 Glik D, Nowak G, Valente T, et al. Youth performing arts entertainment-education for HIV/AIDS prevention and health promotion: practice and research. J Health Commun 2002;7:39-57.

9 Conrad D. Exploring risky youth experiences: popular theatre as a participatory, performative research method. Int J Qual Methods 2004;3:12-25.

10 Joronen K, Rankin SH, stedt-Kurki P. School-Based drama interventions in health promotion for children and adolescents: systematic review. J Adv Nurs 2008;63:116-31.

11 Haines J, Neumark-Sztainer D, Morris B. Theater as a behavior change strategy: qualitative findings from a school-based intervention. Eat Disord 2008;16:241-54.

12 Stephens-Hernandez AB, Livingston JN, Dacons-Brock K, et al. Drama-based education to motivate participation in substance abuse prevention. Subst Abuse Treat Prev Policy 2007;2:11.

13 Rossiter K, Kontos P, Colantonio A, et al. Staging data: theatre as a tool for analysis and knowledge transfer in health research. Soc Sci Med 2008;66:130-46.

14 Gray R, Sinding C, Ivonoffski V, et al. The use of research-based theatre in a project related to metastatic breast cancer. Health Expect 2000;3:137-44.

15 Capturing the audience experience: a Handbook for the theatre. Available: https://itc-arts s3.studiocoucou.com/uploads/helpsheet attachment/file/23/Theatre_handbook.pdf [Accessed July 2018].

16 Brown A, Ratzkin R. Understanding the intrinsic impact of live theatre. patterns of Audience feedback across 18 theatres and 58 productions 2012.

17 Ritchie J, Lewis J. Qualitative research practice: a guide for social science students and researchers. London: Sage Publications, 2003.

18 Noone J, Sullivan M, Nguyen T, et al. Pilot test of interactive Theater to improve parent communication on pregnancy prevention. Arts Health 2013;5:68-80.

19 Sloman A. Using participatory theatre in international community development. Community Dev J 2012;47:42-57.

20 Storey D, Sood S. Increasing equity, affirming the power of narrative and expanding dialogue: the evolution of entertainment education over two decades. Critical Arts 2013;27:9-35.

21 Pelto PJ, Singh R. Community street theatre as a tool for interventions on alcohol use and other behaviors related to HIV risks. AIDS Behav 2010;14:147-57.

22 McGillion C. Animation as a science communication tool in TimorLeste. Sci Commun 2017;39:278-85.

$23 \mathrm{Kemp} \mathrm{J}$. Exploring empowerment issues with student midwives using forum theatre. Br J Midwifery 2009;17:438-9.

24 Lawrence J, Wier J. The use of drama within midwifery education to facilitate the understanding of professional behaviour and values. Midwifery 2018;59:59-61. 